\title{
İskemik inmenin etiyolojik tanısında D-dimer
}

\author{
Zahide Mail Gürkan' ${ }^{1}$, Dilek Necioğlu Örken², Ülgen Yalaz Tekan³ , Lale Gündoğdu Çelebi², \\ A. Zeynel Tak ${ }^{4}$, Hulki Forta ${ }^{5}$, Nezaket Eren ${ }^{6}$
}

\begin{abstract}
ÖZET:
İskemik inmenin etiyolojik tanısında D-dimer

Amaç: İskemik inme, çeşitli etiyolojik nedenleri olan bir hastalıktır. İnme etiyolojik tanısını belirlemeye yönelik ilişkisi keşfedilmiş pek çok belirteçten biri de D - Dimer'dir (DD). Bu çalışmada DD seviyeleri ile inme alt gruplarının ayırıcı tanısı, inme ağırlığı ve prognoz arasındaki ilişkinin incelenmesi hedeflenmiştir.

Gereç ve Yöntem: Çalışmaya Şişli Etfal Eğitim ve Araştırma Hastanesi Nöroloji Kliniğine ilk 24 saat içinde başvuran ilk kez inme geçiren hastalar prospektif olarak alındı. Tüm hastaların ilk 24 saat içinde ve 8-10 gün arasında olmak üzere iki kez DD düzeylerine bakıldı. Hastalarla eşit yaş ve cinsiyet dağılımındaki sağlıklı bireyler kontrol grubu olarak alındı ve bir kez DD düzeylerine bakıldı. Hastalar etiyolojik olarak TOAST kriterlerine göre sınıflandı. Akut dönemde National insitutes of Health Stroke Scale (NIHSS) ile inme ağırlığı, daha sonraki izlemlerde ise Modifiye Rankin skalası (mRS) ve Barthell skalası ile prognozları değerlendirildi.

Bulgular: Bu çalışmaya 15'i kadın, 40 iskemik inmeli hasta ve 12'si kadın olmak üzere 20 sağlıklı kontrol hastası dahil edildi. Çalışmamızda akut dönemde iskemik inmeli hastalarda sağlıklı kontrollere göre DD seviyelerinde anlamlı yükseklik saptanmış olmasına karşın $(p=0,018 p=0,019)$, kardiyoembolik inmesi olanlar ve atriyal fibrilasyonu olanlar diğer gruplarla karşılaştırıldığında anlamlı farklılıklar bulunamamıştır $(p=0,333 p=0,519$ ve $p=0,490 p=0,251)$. Inme ağırlığı ve prognoz ile ilişkisine bakıldığında ise yüksek DD seviyeleri dizabilite ile ilişkili olarak bulunmuştur.

Sonuç: DD iskemik inmenin erken döneminde kullanışlı olabilecek bir belirteçtir. Her ne kadar DD seviyelerini etkileyen çok sayıda faktör varsa da, DD düzeyindeki yükselmenin progresif inmenin bir göstergesi olabileceğini ve prognoza dair bilgiler sunabileceğini söylemek mümkün gibi görülmektedir.

Anahtar kelimeler: İskemik inme, D - Dimer, inme alt gruplarının ayırıcı tanısı, inme ağırlığı ve prognoz
\end{abstract}

\section{ABSTRACT:}

D-dimer levels in etiological diagnosis of ischemic stroke and relationship the prognosis

Background: Objective-Ischemic stroke is a disease with a variety of etiological factors. D-dimer (DD) is one of markers established in the etiological diagnosis of stroke. In this study, differential diagnosis of the subgroups of stroke and the relationship between the severity of stroke and the prognosis is investigated in association with the DD levels.

Material and Metod: In this study, the patients who had a stroke and applied to the Clinic of Neurology at Şişli Etfal Education and Resarch Hospital in 24 hours has been included prospectively. All patients' plasma D-dimer levels has been measured for two times firstly in 24 hours and the second between 8.-10. days. The etiological subgroups were determined according to TOAST criterias. The stroke severity has been evaluated in acute periode by National Insitutes of Health Stroke Scale (NIHSS), the prognosis has been evaluated subsequent periode by Modifiye Rankin scala (mRS) and Barthell scala.

Results: In this study 40 patients with stroke including 15 women and 20 healthy control patients including 12 women were included. In our study, the level of DD in ischemic stroke patients in the early period is found to be higher compared with the healthy controls $(p=0,018 p=0,019)$. But $D D$ levels are not significantly higher in the atrial fibrillation and cardioembolic stroke patients compared with the other groups ( $p=0,490 p=0,251$ and $p=0,333 p=0,519)$. When the relationship between the severity of the stroke and the prognosis is investigated, high DD levels are found to be associated with disabilities.

Conclusion: $\mathrm{DD}$ is an applicable biomarker in the early period of ischemic stroke. Although there are many factors that affect the level of DD, DD levels may be an indicator of progressive stroke and can provide information about prognosis seems to be able to say.

Key words: Ischemic stroke, D-dimer, differential diagnosis of the subgroups of stroke, severity of stroke and the prognosis

Ş.E.E.A.H. Tıp Bülteni 2013;47(1):1-4
'Dr., Medivia Hospital, i̇stanbul-Türkiye ${ }^{2}$ Dr., Şişli Etfal Eğitim Ve Araştırma Hastanesi, Nöroloji Kliniği, İstanbul-Türkiye ${ }^{3}$ Dr., Van Eğitim Ve Araştırma Hastanesi, Nöroloji Kliniği, Van-Türkiye ${ }^{4}$ Dr., Adıyaman Üniversitesi Eğitim Ve Araştırma Hastanesi, Nöroloji Kliniği, Adıyaman-Türkiye

${ }^{5}$ Dr., Serbest Nörolog, i̇stanbul-Türkiye ${ }^{6}$ Dr., Şişli Etfal Eğitim Ve Araştırma HastanesiBiyokimya Kliniği, İstanbul-Türkiye

Yazışma Adresi / Address reprint requests to: Dr. Zahide Mail Gürkan, Medivia Hospital, İstanbul-Türkiye

Telefon / Phone: +90-532-596-9852

E-posta / E-mail: zahidail@hotmail.com

Geliş tarihi / Date of receipt: 29 Ağustos 2012 / August 29, 2012

Kabul tarihi / Date of acceptance: 31 Ağustos 2012 / August 31, 2012 


\section{GíRiş}

Dünya Sağlık Örgütünün verilerine göre iskemik inme gelişmiş ülkelerde üçüncü sırada gelen ölüm nedenidir. Her yıl 5 milyonun üstünde insan inme nedeniyle ölmektedir ve kurtulan altı hastadan bir tanesi 5 yıl içinde diğer bir inme geçirmektedir (1).

İnme alt tiplerinde patolojik süreçler oldukça farkIı işlemektedir. İskemik inmenin önlenme şansı etyolojik nedenine yönelik olarak doğru tedavi edilmesi ile artar. Farklı inme etiyolojileri özgül plazma proteinlerinin ekspresyon paternleri ile ilişkili olabilir. İnme etiyolojisi hakkında kesin bilgiler verebilecek bir belirteç olmamasına rağmen, kimi araştırıcılar, hemostatik belirteçler gibi proteinlerin inme alt tipleri ile ilişkisini keşfetmişlerdir. Bunlardan bir tanesi de D-Dimer' dir (DD) (1). Akut dönemde iskemik inmenin etiyolojisini bilmek hastanın akut tedavi şansını ve başarısını arttırmakta ve inmenin tekrarlamaması için alınacak önlemleri hızlandırmaktadır. Bu bakımdan eğer bir algoritma oluşturulabilirse, etiyolojiye yönelik fikir vermesi açısından kanda ölçülen bir belirteç olan D-dimer kullanışı ı bir yöntem olacaktır.

Çalışmamızda DD düzeylerinin iskemik inmeli hastalarda akut dönemde ve takipte, etiyolojik sınıflamaya katkısının araştırılması ve prognozla ilişkisinin tartışılması hedeflenmektedir.

\section{GEREÇ VE YÖNTEM}

Çalışmaya 2009 yılı Mart ve Ekim ayları arasında, Şişli Etfal Eğitim ve Araştırma Hastanesi Nöroloji Kliniğine ilk 24 saat içinde başvuran iskemik inme geçiren $15^{\prime}$ i kadın 40 hasta prospektif olarak alındı. Başvurusu sırasında 18 yaş altı hastalar, ilk başvuruda laküner inmesi olan, tPA tedavisi alanlar, epilepsi nöbeti olanlar, malignitesi, sistemik inflamatuar ya da infeksiyon hastalığı, diğer serebral sinir sistemi hastalıkları (kanama, kitle, infeksiyon), kafa travması olanlar, başvuru sırasında antikoagülan kullananlar ve derin ven trombozu olanlar çalışmadan dışlandı.

Tüm hastaların ilk 24 saat içinde ve 8-10 gün arasında olmak üzere iki kez D-dimer (DD) düzeylerine bakıldı. Hastaların etiyolojik sınıflaması TOAST kriterlerine göre yapıldı (2). Akut dönemde National Insitutes of Health Stroke Scale (NIHSS) ile inme ağır- lığı saptandı. Hastaneden çıkarken Modifiye Rankin skalası (mRS) ve 3. ve 6. ay takiplerde Barthell skalası ile prognoz değerlendirildi.

Çalışmaya alınmış hastalarla eşit yaş ve cinsiyet dağılımındaki sağlıklı bireyler kontrol grubu olarak alındı ve bir kez DD düzeylerine bakıldı.

DD düzeylerine Şişli Etfal Eğitim ve Araştırma Hastanesi Biyokimya laboratuarında ViDAS cihazı kullanılarak bakıldı.

İstatistiksel analizler için Statistical Package for Social Sciences (SPSS) Windows 17 programı kullanıldı. Tanımlayıcı istatistiksel metodlar (ortalama, standart sapma), ki kare testi, student t testi, korelasyon değerlendirilirken Pearson korelasyon testi kullanıldı. Anlamlılık p<0.05 düzeyinde değerlendirildi.

\section{SONUÇLAR}

Bu çalışmaya 15'i kadın, 40 iskemik inmeli hasta ve 12 'si kadın olmak üzere 20 sağlıklı kontrol hastası dahil edildi. Çalışmaya alınan hastaların ve kontrol grubunun yaş ortalaması sırası ile $62,45 \pm 10,95$ (3890), ve $65,85 \pm 12,91$ (43-80) idi. Hasta grubu ile kontrol grubu arasında yaş ortalamaları ve cinsiyet dağılımları bakımından istatistiksel olarak fark yoktu $(p=0,317 p=0,108)$ Hastaların risk faktörlerinin dağılımı Tablo 1'de gösterildi.

TOAST sınıflamasına göre hastaların $\% 30^{\prime} u$ kardiyoembolik inme, $\% 22,5^{\prime} \mathrm{i}$ aterosklerotik inme ve $\% 47,5$ 'i tanımlanamayan inme olarak sınıflandı.

Hastaların ve kontrol grubunun DD seviyeleri

Tablo 1: Hastaların demografik özellikleri

\begin{tabular}{lll}
\hline & Vaka $\mathbf{n = 4 0}$ & Kontrol $\mathbf{n = 2 0}$ \\
\hline Yaş & $62,45 \pm 10,95$ & $65,85 \pm 12,91$ \\
Cinsiyet (kadın) & $15(\% 37,5)$ & $12(\% 60)$ \\
Atriyal Fibrilasyon & $14(\% 35)$ & - \\
Hipertansiyon & $25(\% 62,5)$ & - \\
Diabetes Mellitus & $7(\% 17,5)$ & - \\
Hiperlipidemi & $18(\% 45)$ & - \\
Kalp hastalığı & $14(\% 35)$ & - \\
Sigara & $9(22,5)$ & - \\
Alkol & $4(\% 10)$ & - \\
Geçirilmiş SVA & $10(\% 25)$ & \\
NIHSS ortalama & $9,45 \pm 6,00$ & \\
mRS ortalama & $2,65 \pm 2,03$ & \\
Barthell 3. ay ortalama & $14,70 \pm 6,88$ & - \\
Barthell 6. ay ortalama & $15 \pm 6,71$ &
\end{tabular}


Table 2: DD seviyeleri

\begin{tabular}{llll}
\hline & Vaka & Kontrol & p değeri \\
\hline DD (ilk 24 saat) & $768,33 \pm 657,21 \mathrm{ng} / \mathrm{ml}$ & $396,58 \pm 238,12 \mathrm{ng} / \mathrm{ml}$ & 0,018 \\
DD (8 - 10 gün arasında) & $808,17 \pm 740,38 \mathrm{ng} / \mathrm{ml}$ & - & 0,019
\end{tabular}

Table 3: AF'u olan hastalarla olmayanların DD seviyelerinin karşılaştırılması

\begin{tabular}{llll}
\hline & AF'si olanlar & AF'si olmayanlar & p değeri \\
\hline DD ilk 24 saat & $867,68 \pm 703,77 \mathrm{ng} / \mathrm{ml}$ & $714,83 \pm 638,55 \mathrm{ng} / \mathrm{ml}$ & 0,490 \\
DD 8 - 10 gün & $1012,40 \pm 925,03 \mathrm{ng} / \mathrm{ml}$ & $710,14 \pm 631,82 \mathrm{ng} / \mathrm{ml}$ & 0,251
\end{tabular}

Table 4: Kardiyoembolik ve aterosklerotik hastaların DD seviyelerinin karşılaştırılması

\begin{tabular}{llll}
\hline & Kardiyoemboli & Ateroskleroz & p değeri \\
\hline DD ilk 24 saat & $1010,03 \pm 839,91 \mathrm{ng} / \mathrm{ml}$ & $691,44 \pm 536,005 \mathrm{ng} / \mathrm{ml}$ & 0,333 \\
DD 8 - 10 gün & $1096,10 \pm 1074,51 \mathrm{ng} / \mathrm{ml}$ & $841,08 \pm 477,17 \mathrm{ng} / \mathrm{ml}$ & 0,519
\end{tabular}

Tablo 2'de gösterilmiştir. Tüm hastaların ilk 24 saat içinde ve 8-10 gün arasındaki DD seviyeleri, kontrol grubuna göre yüksek bulunmuştur (sırası ile $p=0,018$ ve $p=0,019)$. Illk 24 saatte bakılan DD ile inme ağırlığı arasında ilişki olmamasına $(r=0,115 p=0,48)$ rağmen 8-10 gün arasında bakılan DD seviyeleri ile inme ağırlığı ilişkili bulunmuştur ( $r=0,375 \mathrm{p}=0,022)$. Başvuruda daha ağır inmesi olan hastaların ise özürlülük oranlarının yüksek olduğu izlenmiştir $(r=0,555$ $p=0,000)$. DD seviyelerindeki yüksekliğin taburculukta, 3. ve 6. aydaki takiplerimizdeki yüksek özürlülük ile ilişkisi anlamlı düzeylerdedir (sırası ile $r=0,359$ $p=0,023, r=-0,394 p=0,021, r=0,399 p=0,022$ ).

Hem atriyal fibrilasyonu olanlar olmayanlarla, hem de kardiyoembolik inmesi olanlar aterosklerotik inmeli hastalarla karşılaştırılmıştır. Atriyal fibrilasyonu ve kardiyoembolik inmesi olan hastaların DD seviyeleri diğer gruplara göre yüksek olmakla birlikte istatistiksel olarak anlamlığa ulaşamamıştır (sırası ile $p=0,490, p=0,251$ ve $p=0,333, p=0,519)$ (Tablo 3 ve 4).

\section{TARTIŞMA}

Plazma DD seviyeleri, pek çok hastalık ile tromboz ve tromboliz içeren pek çok fizyolojik durumda yükselir (3). Ayrıca DD yaşla beraber de artış gösterir
$(4,5)$. Bilindiği üzere esas olarak pratikte yaygın olarak kullanıldığı alan disemine intravasküler koagülasyon (DIC) ve venöz tromboembolizmdir (VTE). DD seviyesi hastalarda fibrinolitik sürecin varlığını gösteren bir belirteçtir ve koagülasyonun arttığı durumları işaret eder. Sensitivitesi yüksek ancak spesifitesi düşüktür (6).

Joan Montaner ve arkadaşları, inme etiyolojisini aydınlatmaya yönelik plazma belirteçlerinden oluşan geniş bir yelpaze kullandılar ve bunlardan bir tanesi olan DD seviyelerinde, akut, subakut ve kronik dönemlerde yükseklik saptadılar (1). DD seviyesinin yeni bir vasküler olayın göstergesi olabileceği ve prognostik bir role sahip olduğunu gösterdiler (1).

Yükselmiş DD seviyelerinin kardiyoembolik inmenin göstergesi olduğu pek çok çalışmada gösterilmiş ve kardiyoembolik inmelerde diğer inme alt gruplarından belirgin olarak yüksek bulunmuştur $(1,7,8,9,10)$. Dougu ve arkadaşları atriyal fibrilasyonu olan hastaların ayrı bir grup olarak değerlendirildiği çalışmalarında, kardiyoembolik inmesi olanlar arasında özellikle atriyal fibrilasyonu olan hastalarda DD seviyelerinin daha yüksek olduğunu göstermişlerdir (7). Bunun yanı sıra erken klinik progresyon ve prognoz ile DD seviyeleri arasında anlamlı ilişki saptanmıştır $(11,12,13)$.

Çalışmamızda akut dönemde iskemik inmeli has- 
talarda sağ|ıklı kontrollere göre DD seviyelerinde yükseklik saptanmış olmasına karşın, kardiyoembolik inmesi olanlar ve atriyal fibrilasyonu olanlar diğer gruplarla karşılaştırıldığında anlamlı farklılıklar bulunamamıştır. Bu sonuca tüm grupta atrial fibrilasyonlu hasta oranının düşük olması neden olmuş olabilir. İnme ağırlığı ve prognoz ile ilişkisine bakıldığında ise yüksek DD seviyeleri dizabilite ile ilişkili olarak bulunmuştur. Hızlı sonuç alınabilen, kolay ve maliyeti düşük olan bu incelemenin iskemik inmenin erken döneminde acil koşullarında kullanılması uygun olabileceği düşünülmüştür. İnmenin alt grup-

\section{KAYNAKLAR}

1. Montaner J, Perea-Gainza M, Delgado P et al. Etiologic diagnosis of ischemic stroke subtypes with plasma biomarkers. Stroke 2008;39:2280-2287.

2. Adams HP Jr, Bendixen BH, Kapelle J et al, the TOAST investigators. Classification of subtypes of acute ischemic stroke: definition for use in multicenter clinical trial. Stroke 1993;24:3541.

3. Haapaniemi E, Tatlisumak T. Is D-dimer helpful in evaluating stroke patients? A systematic review.) Acta Neurol Scand 2009; 119(3):141-50.

4. Ono N, Koyama T, Suehiro A, Oku K, Fujikake K, Kakishita E. Clinical significance of new coagulation and fibrinolytic markers in ischemic stroke patients. Stroke 1991;22(11):1369-73.

5. Squizzato A, Ageno W, Finazzi S, Mera V, Romualdi E, Bossi A, Venco A. D-dimer is not a long-term prognostic marker following acute cerebral ischemia. Blood Coagul Fibrinolysis 2006;17(4):303-6.

6. Sumney M. D-dimer: past, present, and future. Fall 2007.

7. Dougu N, Takashima S, Sasahara E et al. Differential diagnosis of cerebral infarction using an algorithm combining atrial fibrillation and D-dimer level. Eur J Neurol 2008;15(3):295-300. ları ve hastalığın seyri hakkında fikir vermesi açısından önemlidir. Erken dönem tedavileri belirlemede ve rekürrensleri önlemede yararlı gözükmektedir.

Sonuç olarak DD iskemik inmenin erken döneminde yararlı olabilecek bir belirteçtir. Her ne kadar DD seviyelerini etkileyen çok sayıda faktör varsa da, DD düzeyindeki yükselmenin progresif inmenin bir göstergesi olabileceğini ve prognoza dair net bilgiler sunabileceğini söylemek mümkün gibi görülmektedir. Ancak belli algoritmaların oluşturulması ve standardize yöntemlerin belirlenmesine ihtiyaç olduğu düşüncesindeyiz.
8. Koch HJ, Horn M, Bogdahn U, Ickenstein GW. The relationship between plasma D-dimer concentrations and acute ischemic stroke subtypes.J Stroke Cerebrovasc Dis 2005;14(2):75-9.

9. Ageno W, Finazzi S, Steidl L, Biotti MG, Mera V, Melzi D'Eril G, Venco A. Plasma measurement of D-dimer levels for the early diagnosis of ischemic stroke subtypes. Arch Intern Med 2002; 9-23;162(22):2589-93.

10. Isenegger J, Meier N, Lämmle B et al. D-dimers predict stroke subtype when assessed early. Cerebrovasc Dis. 2010;29(1):82-6

11. Barber M, Langhorne P, Rumley A, Lowe GD, Stott DJ. D-dimer predicts early clinical progression in ischemic stroke: confirmation using routine clinical assays. Stroke 2006;37(4):1113-5.

12. Barber $M$, Langhorne $P$, Rumley A, Lowe GD, Stott DJ. Hemostatic function and progressing ischemic stroke: D-dimer predicts early clinical progression. Stroke 2004;35(6):1421-5.

13. Feinberg WM, Erickson LP, Bruck D, Kittelson J. Hemostatic markers in acute ischemic stroke. Association with stroke type, severity, and outcome. Stroke 1996;27(8):1296-300. 